\title{
De la autonomía a la comunidad. Hutcheson y el continuo trajinar entre el sentido moral y la benevolencia
}

\author{
JULIO SEOANE \\ Universidad de Alcalá de Henares
}

Hutcheson es el teórico del sentido moral. $Y$ por tal se entiende una concepción de nuestro comportamiento ético y político que, a la par que sienta las bases de lo que se ha instituido como concepción liberal de la política, es incapaz de considerar nuestro laborar en el mundo sin referirlo directamente a las imágenes comunitarias de lo que sea el bien. Lo que Hutcheson nos puede enseñar es que nuestras discu- siones actuales en filosofía política malentienden nuestra tradición y son incapaces de leerla al completo: precisamente a poco que se mire en nuestro pasado se comprenderá que nunca han caminado por separado las concepciones entre un estricto y autónomo sentido moral que juzga desde sí y una benevolencia comunitaria que le da los significados con los que juzgar.

\section{El sentido moral}

El punto de partida de Hutcheson es bastante simple: considera que las nociones fundamentales de la ética y de la estética —el bien, lo bello, lo correctoson ideas simples derivadas directa o indirectamente de las impresiones de los sentidos. Obviamente no de los cinco sentidos, sino de un sentido moral y un sentido de la belleza merced a los cuales recibimos las ideas placenteras de «regularidad, orden y armonía». Hutcheson llama a estos sentidos "sentidos internos». Son sentidos porque las ideas de virtud y belleza son recibidas pasivamente y no están sujetas a alteraciones que pudieran venir por el ejercicio de la voluntad, y son internos no porque supongan una reflexión o una dependencia de las operaciones mentales (como sucedía con Locke), sino porque sus sensaciones no provienen de ningun órgano de los sentidos en particular. El sentido moral es un sentido interno cuyas percepciones son sensaciones externas que no se describen correctamente como ideas complejas, pues no son ni arbitrarias ni construidas, sino que son naturales e irreductibles (Fate Norton, 1985, p. 403).

Ésta es una de las definiciones que da Hutcheson del sentido moral: «No debemos imaginar que este sentido moral más que otros sentidos suponga ideas innatas o conocimiento o proposiciones prácticas: entendemos por tal solamente una determinación de nuestras mentes a recibir agradable o desa- 
gradablemente ideas de acciones, cuando éstas caigan bajo nuestra observación, anteriormente a cualquier opinión de provecho o pérdida que pudiera avenirnos de ellas» (Inquiry, secc. 1, VIII). Ante las acciones humanas, el sentido moral automáticamente reacciona de dos formas: o se place $-\mathrm{y}$ con ello apruebao se duele $-y$, de este modo, desaprueba-. Aquí se sitúa el origen de la posición de Hutcheson: en la aprobación o desaprobación por parte del sentido moral —en su placer o displacer - está el punto final de cualquier justificación $\mathrm{y}$ argumentación moral.

Pero no debemos creer que la percepción moral sea una experiencia subjetiva, ni que los juicios morales sean simples expresiones de esa experiencia (Haakonssen, 1986, p. 73); por el contrario, Hutcheson tiene la idea de que el sentido moral es un esquema de percepción de la realidad connatural a todos los hombres, un esquema universal que se place con lo bueno en general y no con aquello que satisface intereses particulares. Lo bueno nos da placer no porque excite y satisfaga a nuestros sentidos privados, sino simplemente porque estamos hechos de tal manera que sentimos placer cuando una acción satisface el esquema formal de la recepción de los actos morales - y éste, el sentido moral, se satisface con actos benevolentes, encaminados a la felicidad general, no egoístas.

Mucho se ha discutido. sobre la inmediatez del placer que surge al contemplar una acción benevolente. Unos autores, tomando al sentido moral como un «esquema mecánico», han considerado que Hutcheson creía que nos placemos automáticamente en el momento en que percibimos una acción benevolente. Otros han preferido leer en Hutcheson que lo bueno, aunque no es una idea compleja, sí es un complejo de ideas que para componerse precisa del auxilio de la razón. La verdad es que Hutcheson puede complacer a unos y otros sin darles nunca por cntero la razón. Su idea es que el placer o displacer surge de manera inmediata en el sentido moral, pero eso no significa que surja automáticamente, porque muchas veces la misma razón ayuda a corregir ciertas percepciones. Por muy inconsistente que a sus exégetas les haya podido parecer, Hutcheson estaba convencido de que el sentido moral aprueba o desaprueba automáticamente contando simplemente con la pura recepción de sensaciones morales externas, y creía también que eso no estaba reñido con que pudieran existir consideraciones de la razón que, sin poder demorar en mucho el juicio - pues las cosas de placeres tienen poca paciencia-, podían intervenir en la percepción de las sensaciones morales externas (y en tanto externas, totalmente ajenas a nuestra voluntad). Las verdades morales no son autoevidentes ni cognoscibles por lá razón, es cierto, pero sí que son ordenables y justificables de una manera sistemática, y eso es lo que hace que el sentido moral no sea un sentido meramente receptivo, sino también compositivo (y ello sin que su estrecha vinculación con la razón objete el que en verdad sienta datos morales). Hutcheson se preocupa por recalcar que la razón tan sólo ayuda a que las sensaciones morales sean naturales, a que no se falsifiquen 
por la acción de prejuicios o engaños que a modo de unas gafas mal graduadas nos hicieran ver la realidad como no es, pero lo cierto es que esta mera función de ordenamiento y corrección (de salvaguarda del correcto sentir) no es únicamente una función de limpieza de las sensaciones. $O$ siéndolo, en el momento en que decide qué y dónde limpiar, ya no es una limpieza inocente. Tal salvaguarda se logra creando virtudes y objetivos que son capaces de modificar el objeto de placer. La recepción del placer es tanto un camino que va de la acción al sentido moral, cuanto a la inversa: el sentido moral tiende a recibir con placer lo que la razón le muestra que sirve o conduce a la benevolencia - a la felicidad universal.

Este «doble origen» de la moral es el que ha propiciado diferentes interpretaciones del sentido moral. Los críticos más comprensivos han supuesto que Hutcheson está buscando sin conseguirlo «una vía media entre un ingenuo realismo, según el cual las cualidades estéticas y morales existen en los objetos independientemente de la referencia a algún observador, y un anticognoscitivismo, según el cual las juicios morales se reducen a la experiencia o a la expresión de los sentimientos" [T. D. Campbell, 1982, p. 171]; pero lo cierto es que el propósito de Hutcheson no es encontrar una «vía media» porque, simplemente, no ve problema en ser realista y cognitivista al tiempo. Compuso su pensamiento con ambos convencimientos sin llegar nunca a ser contradictorio. En efecto, si intentamos establecer qué sea el sentido moral atendiendo únicamente a las definiciones que se nos ofrece del mismo, entraremos en las infinitas discusiones de saber si es un mero sentido, un esquema de la sensación o un modo de percibir de la razón; mi idea es que el sentido moral hay que entenderlo como un engranaje más dentro del pensamiento moral de Hutcheson. Un engranaje cuya consistencia con el conjunto le hace sobreponerse a las ambigüedades iniciales de su primera definición (algo así como si pudiéramos hacer funcionar una máquina con una pieza que a todas luces es de otra máquina). En lo que sigue creo poder dar razones para sustentar mi idea.

\section{La benevolencia}

Hutcheson piensa que todas las acciones humanas tienen a su base dos pasiones originales: la benevolencia y el egoísmo. Ambas son innatas, componen la formación de nuestra individualidad, pero con una se complace el sentido moral y con la otra no. ¿Qué es realmente la benevolencia? En las secciones I y II del Inquiry la benevolencia se define, de manera hedonista, como una afección cuyo objeto es la felicidad de los demás. En la sección III se intenta un analisis psicológico más complejo que no aparece hasta el Essay (y las Mllustrations). En todo caso la idea básica de Hutcheson es que, al igual que resulta innegable que es en la felicidad propia donde encontramos mayor contento, parece que el sentido moral debería encontrar aún más contento en la felicidad de todos 
los hombres, alli donde no hubiera hombre infeliz. De esta manera, nuestro sentido moral además de complacerse con nuestra propia felicidad se complacerá (iy cuánto más!) sintiendo una felicidad universal. Según esto, razona Hutcheson, los actos benevolentes, que son los que conducen al bien general o público, son los que en más alto grado complacen al sentido moral. Un acto será virtuoso - y dará placer- en tanto proceda de la benevolencia - y se dirija al bien público-. Como se ve, así queda vinculado el sentido moral (individual, solipsista, atómico, puro esquema de la recepción) con el interés por el bien general, por la producción efectiva de bienes públicos. Esta vinculación compone a la benevolencia en un doble estatus. Por un lado, es una pasión que de manera natural surge en el hombre; es una pasión desinteresada que elige su rumbo siempre al margen de cualquier inclinación personal (si fuera interesada sería una acción egoísta - que es el otro tipo de pasión natural-, lo cual no satisfaría al sentido moral). Pero si la benevolencia se presenta como pasión también, por otro lado, es un afección que recapacita y mira siempre con un ojo puesto en el sentido público (que para Hutcheson es la determinación a complacerse con la felicidad de los otros y displacerse con su miseria). Su interés por el bien común - como afección- hace que la benevolencia, sin tener interés ninguno - como pasión-, sea de gran interés social. Quiero ahora tratar algo detenidamente estos dos «aspectos» de la benevolencia.

\section{Contra el egoísmo}

El primer enemigo al que mira Hutcheson es Mandeville. Otros son, por supuesto, sus oscuros objetos de debate, pero no es casual que una parte del largo subtítulo de su primer libro, el Inquin, sea «donde los principios del Conde de Shaftesbury son explicados y defendidos conta el autor de la Fábula de las Abejas». La cuestión no era trivial para la época. Mandeville había tomado la bandera de Hobbes y era el representante más cxtremado de la creencia de que toda acción humana se deriva del propio interés y, en último término, no somos sino seres asociales y egoístas que nos reunimos en sociedad a fin de llevar a cabo de mejor manera nuestros intereses. L a originalidad de Mandeville consistía en que consideraba la tarea del filósofo como un desenmascaramiento que pusiera en claro que tras los conceptos de virtud laten ocultas las pasiones, intereses y vicios privados, que son los que a su entender nos mueven y traen prosperidad y riqueza. Quiero dejar bien claro que esta posición no se debe circunscribir solamente a Mandeville, sino que, muy por el contrario, uniforma en mayor o menor medida una tendencia que ha sido una de las fuentcs de nuestro presente. Mandeville es el representante más cxtrcmado de un «liberalismo» que hoy aparece bajo la idea tan mandevilleana de que el mundo no es sino la composición que nuestros intereses consensúan. 
La idea que Mandeville extremaba era que nuestros actos, aun realizados por interés propio, podian traer beneficios públicos y que era precisamente en función de esos beneficios como se podía juzgar una acción. Esto preocupaba a Hutcheson, cuyo camino andaba muy cercano a la senda que proponía Mandeville. Si la última palabra del placer de nuestro sentido moral - de la aprobación- es el bien público que produzcan nuestros actos, entonces estamos a un pequeño paso de pensar que lo verdaderamente válido es simplemente atender a las consecuencias públicas de nuestros actos, independientemente de que procedan de nuestros vicios privados o de nuestra privada inclinación al bien. Estamos a un paso del panal donde el bien público procede de la vida poco virtuosa de los hombres y no de la aprobación de las buenas acciones por parte del sentido moral. Ante esto Hutcheson toma precauciones de una doble manera. En primer lugar, repite su concepción del sentido moral: el sentido moral es una «determinación de la mente a recibir alguna idea desde la presencia de un objeto que nos aparece independiente de nuestra voluntad» (Inquiry, secc. 1, I), y tal independencia es precisamente lo que permite formar un sistema coherente de creencias con el cual nos complacemos (téngase en cuenta que Hutcheson tiene aquí en mente un constante paralelo entre virtud y belleza, y que crec que nos inclinamos naturalmente hacia las cosas bellas buscando un sentido de completud y perfección ínsito en nosotros mismos).

En segundo lugar, Hutcheson añade una caracterización al sentido moral: para hablar de virtud es preciso que el acto haya sido hecho voluntariamente en vistas a la virtud. Juzgar moralmente es juzgar la acción y la intención del individuo que hace el acto, y esto, al decir de Hutcheson, es algo que cotidianamente hacemos al evaluar una conducta. De hecho, el sentido moral percibe no sólo la consideración de la acción externa - la pasión-, sino también el motivo por el cual el agente la hace - la afección-; en base a ambos términos, la afección y la pasión, juzga (aunque el verbo «juzgar» es muy inexacto aquí y debiera decirse simplemente «se place y, placiéndóse, aprueba»).

¿Cómo sabemos de las intenciones internas y particulares de cada cual? Hutcheson piensa en lo difícil que a veces resulta la percepción de la afección; siempre se puede dar el caso de que, por ejemplo, creamos que el motivo de una acción es la benevolencia siendo en verdad el interés, o también es posible equivocarnos al percibir la pasión, ya que no son pocos los casos en que, tomamos en serio las pasiones sin saber que son fingidas, ni escasos son los sucesos en que las pasiones no nos son claras. Ciertamente aparece en este punto un problema que Hutcheson anota dentro de las dificultades del juicio moral, y no le importa hacerlo porque lo que quiere poner en claro es que, aun cuando los efectos de una acción realizada por el interés propio coincidan con los de una acción benevolente, no por ello la decimos virtuosa; si es buena para la comunidad diremos que es una acción buena para la comunidad, pero no por eso moralmente buena; por el contrario, nos es evidente que es una acción egoísta. El juicio moral ha de ser algo más que considerar 
las consecuencias de las acciones, pues de lo contrario deberiamos aprobar moralmente a un limonero porque nos proporciona frutos útiles.

Para esta caracterización de la benevolencia Hutcheson debía de creer que el hombre se complace con la sociabilidad - eso y no otra cosa es complacerse con el bien público-, y éste es realmente el punto de fricción con Mandeville. En último término, el desagrado que Hutcheson siente ante Mandeville parte de la negativa de nuestro autor a admitir que por naturaleza el hombre es primordialmente egoísta; su idea es que por naturaleza somos sociables, buenos y benevolentes tanto como egoístas y malvados, y ante la disyuntiva de «vicios o virtudes» lo cierto es que nos complacemos más con estas últimas. Hutcheson cstá convencido de que existe un estado del espiritu, que podríamos llamar empático, según el cual cuando vemos a alguien que sufre o en un estado de miseria, volvemos hacia él nuestros pensamientos y sentimos piedad y ganas de aliviar su pena. Y esto que nos sucede sin ánimo de obtener provecho ninguno, sino espontáncamente, por pura benevolencia (System, libro 1, cap. 2, III), no tiene un equivalente en la malevolencia. Por ello es posible pensar que nos complacemos - y mucho- en las acciones que son benevolentes y que gustamos de vivir en sociedad no porque así satisfagamos de mejor manera nuestros intereses, sino porque la propia vida en común es gozosa. Puestos a argumentar contra Mandeville, no es ésta una argumentación muy concluyente, pero es que ante Mandeville, Hutcheson recuerda al Platón del Gorgias: la única solución es decir que caben tanto él como Mandeville, que allí donde se da una explicación egoísta también cabe otra benevolente y que, al final, incluso si Mandeville tuviera razón, merece la pena desarrollar la benevolencia, pues promete ser bien público más seguro que el egoísmo del panal.

\section{El ámbito del sentido público}

Una vez que hemos apostado por iniciar el camino de la virtud desde el sentido moral y hemos confiado en una benevolencia instintiva, la razón parece que tiene poco que hacer (salvo en los departamentos de Limpieza y Archivo). De hecho, Hutcheson considera que las argumentaciones racionales suelen mover muy poco a la hora de realizar una acción u otra (éste es el camino que heredará Hume). Pero, ïinstintivo significa sin razón? En realidad lo que Hutcheson tienen en mente es que, a la hora de aprobar una acción, si bien es cierto que no podemos andar buscando fundamentaciones racionales, no lo es menos que es precisa una cierta reflexión. Hutcheson llama pasiones sosegadas o serenas (calm passions) a las pasiones que, sin dejar de ser primeramente instintivas, espontáneas y naturales, han sido capaces de atender a las reflexiones del entendimiento.

Es necesario recomendar un talante sereno para la virtud a fin de no extraviarnos en los primeros deseos (los cuales, aun siendo benevolentes, se pueden 
perder en la violencia inicial de las pasiones), pero es preciso también que este sosiego de la reflexión no degenere en una quietud racional, pues sicmpre ha de quedar alguna inclinación o instinto: «de lo contrario no podría haber acción de ningún tipo» (Illustrations, p. 290). Las pasiones sosegadas son precisamente ese lugar donde la pasión instintiva y desinteresada de la benevolencia se toma un interés en sus objetivos; son el modo en como la inherente inclinación a la benevolencia - tanto como la inclinación hacia el egoísmo- se compone con una reflexión sobre sus consecuencias. En esa reflexión el hombre no sólo establece caminos y modos de actuación, también sopesa y calcula el efecto de los actos (además de sentir su inherente inclinación al egoísmo o a la benevolencia). Así se toman la decisiones morales.

$\mathrm{Si}$ la razón quiere decir algo en cuestiones de moralidad no lo puede hacer imponiendo sus dictados; más bien ha de charlar y discutir con las pasiones, sopesando y calculando sus objetivos y resultados. Las pasiones sosegadas, en último término, son el ámbito de la prudencia del hombre virtuoso, aquel que actúa pasionalmente - y recordemos que benevolencia y egoísmo son las dos pasiones básicas-, pero siempre acompañando sus pasiones de cierta reflexión. La benevolencia está en este doble ámbito de la pasión y la afección: aparece de modo innata, pero sólo nos complace cuando ha conseguido - de manera sincera-bien público.

\section{La benevolencia como relato público}

Cuando Hutcheson se enfrenta a la pregunta de cómo podemos promover la benevolencia, tiene buen cuidado de no responder que en base a premios y castigos. Ésta es una respuesta peligrosa que podría confundir la benevolencia con la beneficencia, pues podría implicar el hacer actos benevolentes por micdo al castigo o por interés en el premio; icómo la promovemos entonces? Creo que la idea que recorre toda su obra es que la benevolencia se establece en los relatos que nos educan moralmente. ¿Por qué educación moral? Sin razón a priori y desconfiando de la pura ebullición natural de las pasiones, Hutcheson no podía menos que acudir a una educación moral a la hora de promover los comportamientos conducentes al bien público: en ellos se presentará lo que nos va a complacer, y tal placer es lo que nos hará imitar la benevolencia contada. ¿Por qué relatos? Creo que Hutcheson no podía considerar una educación moral como la enseñanza de un código articulado y fundamentado, en tanto ello ofendería al carácter pasional de la benevolencia. La moral, como hemos visto, no es racional y por ello no se puede establecer en un sistema argumentativo más o menos cerrado, pero su carácter sí se aviene bien con una educación en la que se presentaran los modclos de talante sereno, las evidentes beneficios del bien común y, en suma, se nos animara a actuar siempre según ese placer interno al que a veces, por medio de engaños, enclaustran los ropajes que impone la moda. 
A fuer de ser sinceros, hay que decir que Hutcheson nunca contestó directamente al modo en cómo se ha de promover la benevolencia; es cierto que se desmarcó de la promoción en base a premios y castigos, que en varios lugares escribe que para fortalecer nuestra benevolencia debemos ir con buenas compañías, leer buenos libros, etc., pero nunca llega a proponer que la benevolencia se establezca a través de nuestros relatos sociales. Mas si, por un lado, la correlación entre los juicios y las cualidades morales es objetiva y puede decir que este juicio es verdadero y éste cs falso (el sentido moral, no lo olvidemos, no es mera sensación del individuo particular) y, por otro lado, es evidente que nuestra motivación hacia el juicio moral es subjetiva y «emocional», en tanto tal juicio parte de lo que complace a cada quien, la moral solamente puede desarrollarse desde una educación que nos enseñe -que nos cuente- dónde queda la fclicidad gencral. Esta felicidad general establecida por la educación moral es una verdad moral y, por tanto, agrada a cada individuo en particular, y támbien, en tanto es capaz de agradar a cada individuo en particular, es una verdad general.

Como ya he dicho, Hutcheson propone que la benevolencia es tan innata como el interés propio. Ambos son los dos instintos originarios con los que nacemos. Pero en todos los comentaristas, al menos los de este siglo, se deja leer que, de haber nacido un poco más tarde, en lugar de haber dicho que la benevolencia - y el interés - es innata, bien podría haber planteado que poseemos un instinto de benevolencia que se desarrolla a través de la educación, la historia, la vida social, etc. Hutcheson todavía es muy joven para estas cosas, mas su idea, en realidad, no es que nazcamos amando al mundo tanto como a nosotros mismos. De hecho, Hutcheson opina que, en puridad, la benevolencia no es algo connatural al hombre, pues lo natural es que busque su propia felicidad y, por extensión, las de sus más allegados; pero lo que sí es natural es que nada en la naturaleza humana nos impide adquirir la benevolencia y desarrollarla (Roberts, 1973, p. 13). Esta adquisición y desarrollo se hace sobre la base de educar e ilustrar las pasiones sosegadas. No es extraño que la más alta virtud, la benevolencia hacia los enemigos y el amor a los malos, sea, más que un objetivo de la moral, un hito de santidad que se cuenta como límite máximo al cual aspirar. Son precisamente esos hitos, esos relatos del máximo bien, en definitiva, los que valen para la promoción de la benevolencia, que de este modo no sólo nos está diciendo «haz el bien público», sino que está creando una serie de narraciones en los que ese bien público se ve contado. Sc ve establecido.

Esto trae una primcra consecuencia evidente: no podemos dar una definición para todo tiempo y lugar de la benevolencia porque, aunque lo natural es complacerse siempre con la bencvolencia, eso no implica que ésta sea siempre la misma. Sabemos que la benevolencia es aquello que promueve intencionadamente el bien público, sabemos que lo natural es promoverlo, que lo natural es complacerse con él, que lo natural es todo el proceso que, desde 
el sentido moral, nos hace afectarnos por los actos sociales, pero no hay contenidos «naturales» (y son los contenidos los que, al cabo, se aprueban o desaprueban porque dan placer). Mandeville y Hobbes tenían razón: por naturaleza somos egoístas; pero se olvidaban de que por naturaleza también somos benevolentes. Ahora bien, una vez añadido esto, Hutcheson tiene mucho cuidado en recordarnos que, si bien la benevolencia y el interés son naturales, sus contenidos no lo son. Muy por el contrario, el arte de la vida humana consiste en primar, día a día, unas pasiones sobre otras a fin de conseguir los más altos grados de bien público. Bien público hecho de modo sincero, eso sí (y para ello vale la cducación: para enseñarnos el placer de autentificarnos con nuestros actos), pero qué sea ese bien público es algo que dependerá del lugar, el tiempo, las tradiciones particulares, la climatología ... No creo forzar mucho a Hutcheson si digo que benevolencia es el acto que hace bien público, acto hecho con intención de bien público y que crea una historia, un relato, del bien público. Al cabo, la bcnevolencia crea el sentido de lo público, es decir, crea toda la extensión de la palabra «sociedad».

Aprobar las acciones que hacemos o que vamos a hacer, fijar el curso de nuestra actuación $y$, en definitiva, de nuestra identidad, es mirar al bien público y complacernos con él. Y esto es importante porque complacerse con el bien público significa identificamos con nuestros actos, que son actos primeramente sociales. Protestando contra Mandeville, Hutcheson ya propuso que nuestra misma identidad ha de ir tomando cuerpo a través de la benevolencia y que, en último término, se es virtuoso no sólo haciendo lo bueno por deber o por algún otro mandato contractual, sino simplcmente siendo virtuoso, sintiendo como propios los actos benevolentes. Nuestro placer, nuestra felicidad, aparece en la sincera identificación con una comunidad bien ordenada, gozosa y feliz. Hutcheson no dejaba de ser un pastor con la obligación de predicar a sus feligreses al menos una vez por semana.

La identificación del individuo con la comunidad benevolente (que con sus juicios y actuaciones compone) está en las antípodas del hombre asocial de Mandeville (social precisamente por asocial, porque sólo en sociedad es capaz de llevar a cabo sus vicios individuales). La apuesta inicial no puede ser más kantiana: elegimos la benevolencia sin interés ninguno. Pero tal elección no supone mérito moral, éste aparece cuando a lo elegido se unen beneficios públicos, cuando hay bien para la comunidad. Mucho nos podría hoy aportar esta estrecha vinculación entre el sujeto autónomo y su comunidad, porque es la preocupación por verme reflejado en mi comunidad y reconocerme en los relatos de benevolencia (reconocerme tanto que me complazco con ellos); pero sobre lo que quiero llamar la atención es que, al intentar reconocer «sinceridad» en la actuación, esto es, al propugnar la identificación del individuo autónomo con el proyecto colectivo de la comunidad que fija la benevolencia, la reflexión moral ha de juzgar la vida del individuo no como una suma de actos virtuosos, sino como el conjunto de esos actos configurando una vida. No cabe aquí sino una educación moral en torno a relatos de benevolencia. 


\section{El cálculo}

Como hemos visto, la benevolencia tiene que ver con el ámbito donde se evalúa la relacción que existe entre la acción (que persigue el bien público) y su motivo (su sinceridad). Pero una vez pasado este ámbito, también es preciso evaluar la cantidad efectiva de bien público que tal acción ha proporcionado. La pasión que conduce la vida moral es la benevolencia - también lo es el egoísmo- que nos inclina hacia el bien público $\rightarrow$ al privado-; pero el sentido moral no se complacerá con estas pasiones, sino una vez que han sido evaluadas, sopesadas y una vez que se haya comprobado cuánto bien público trajo la pasión que al bien público se inclinaba. Obviamente, a mayor cantidad, mayor placer para el sentido moral.

El sencillo mundo del sentido moral - que recibe inmediatamente el biense complica y pide una evaluación, un cálculo de la cantidad de bien público en que se ha expresado el acto. La acción del individuo pudiera partir de ideas y propuestas nobles y bondadosas, pero es preciso ver cuál es su realidad efectiva porque a la hora de juzgar el mérito de una acción inevitablemente se han de sopesar motivo y acción. Llegado a este punto en que la benevolencia ha de expresarse en el mundo a través de las acciones útiles para la comunìdad, Hutcheson se plantea la posibilidad de que una acción motivada por una buena intención pudiera traer más bien público que otra también motivada por una buena intención. Aquí es donde surge el concepto de cálculo que servirá para decidir cuál de esas dos acciones es más estimable. Hutcheson piensa que alguien que causa un daño, aun actuando por el bien público, no puede tener el mismo mérito - moral o político- que quien da en el clavo con su actuación. Pues bien, a la hora de evaluar un carâcter e interactuar con él según esa evaluación, el cálculo es básico. Un cálculo que estime la cantidad de bien público aportada por el comportamiento benevolente y que saque de su posible ensimismaniento al juicio moral. Hutcheson es cl primcro autor que establece la máxima utilitarista según la cual la acción es mejor cuando consigue la mayor felicidad para el mayor número, pero más que por este «logro filosófico», me interesa el cálculo porque es plantear que, si es cierto que se puede uno complacer en su personal y atómica recepción del mundo, no lo es menos que tal sentido moral ha de cotejarse con la realidad merced a un cálculo que evalúe y realice un balance de las consecuencias de los actos junto con las intenciones del individuo. Al poner el objetivo moral en la benevolencia, no hay moralidad con uno mismo que no sea política, no hay modo de creer que el cultivo de sí aísla del mundo.

Aunque el cálculo cvalúa la cantidad de benevolencia de los actos - de bien público-, se mueve en un nivel muy diferente al de ésta. Se mueve en el nivel de la utilidad que, como Hutcheson advierte, es algo muy poco constante en nuestro mundo. Unas veces se quieren unas cosas, otras veces se prefieren otras diferentes. El caso es que los objetivos de la benevolencia 
pueden variar o pueden expresarse trayendo malas consecuencias; mas lo interesante es que, aunque cambien los objetivos de la benevolencia o, más exactamente, aunque varíen los baremos de utilidad que dan la gradación de cuánto bien público se promueve con una acción determinada, el servir al bien público permanece como lo único que proporciona placer al sentido moral. Algunos intérpretes han señalado un «cierto relativismo» en la obra de Hutcheson que no se compadece con su primer deseo de predicar un sentido moral universal (precisamente para poder acordar a los hombres en cicrtas normas y comportamientos universales). Este relativismo es cierto en la medida en que el mismo Hutcheson admitía que cada diferente sociedad tiene diferentes conceptos de benevolencia. Pero debiera añadirse que, aun diferentes, esos conceptos son siempre de la benevolencia, del bien público. ¿No hay conceptos, ideales, derechos homogéneos? ¿No hay propuestas inapelables? Bien, la idea de Hutcheson es que, si es cierto que existe un «contextualismo» de la benevolencia, no es menos verdad que cualquier ser racional que con sosiego evalúe una acción siempre podría averiguar, por su razón, si proporciona felicidad a los individuos de una comunidad, siempre sabrá decir si es buena o si motivada por el egoísmo -y si esto último, rechazarla-. A primera vista esto sólo parecería posible porque existen unos valores objetivos en los que todos acordamos universalmente (así, por ejemplo, los de propiedad, protección de la vida, etc.) y en cierto modo hay que reconocer que Hutcheson siempre comienza su discurso con la admisión de valores universales. Pero no le parece muy útil el quedarse en este punto, pues considera que por muy universales que sean, el nivel que tiene relevancia para el discurso moral es aquel donde esos valores universales se especifican - se hacen realidad-, y en tal especificación se jerarquizan de distintas maneras, cobran diferentes importancias. El derecho a la propiedad, por ejemplo, no tiene la misma relevancia en todas las sociedades, sin que podamos, además, decir que en unas sociedades, allí donde, por ejemplo, el sentido de propiedad es básico, el sentido moral se complazca más o menos. Pero si no hay actos benevolentes válidos para toda sociedad, ¿cómo es posible, entonces, que la evaluación sosegada dé con la justa calificación moral?

No se plantea Hutcheson que eso que da felicidad sea siempre lo mismo en todas las situaciones y comunidades; pero no lo hace porque, quizás algo ingenuamente, supone que, si todos deseamos la felicidad de todos y es posible un cálculo de felicidades que diga dónde hay más y dónde menos felicidad (y, además, sepa que el sentido moral encuentra mayor placer donde más felicidad hay), entonces parece lógico creer que la humanidad se tiende a unificar bajo conceptos, têrminos, leyes y derechos que persiguen csa felicidad no ya universal, sino de todos y cada uno de los hombres, mujeres y niños de este mundo. Ante la pregunta siempre persistente de cómo es que no hay actos benevolentes válidos en todo tiempo y lugar, creo que la única explicación es que Hutcheson supone que el juicio sosegado evalúa siempre contando 
con todo un cúmulo de relatos morales que ponen en marcha virtudes y asentimientos sociales. Y aquí sí que tenía razón Mandeville: todas las virtudes son socialmente creadas. Pero el acierto de Mandeville le importa muy poco a Hutcheson: puede que sean socialmente creadas, pero son nuestras virtudes y desde ellas cualquier ser racional sabe distinguir lo que se hace de manera egoísta, sin atender al bien público (el cual, de este modo, queda establecido no tras una benevolencia objetiva y neutral, sino en función de una benevolencia creada, actualizada a cada momento). De aquí que el urelativismo» de Hutcheson no esté reñido con la creencia de que existen valores y virtudes - ino diríamos derechos? - tan importantes para la vida publica que su infracción es intolerable. Cierto que son virtudes creadas, como Mandeville había creido, pero eso no impide que pasen a constituir bienes públicos (recordemos que la benevolencia habla de bienes públicos y no de bienes naturales o racionales). Desde ese momento son irrenunciables. El sentido moral se complace con lo que hemos dicho que es el bien. Porque, aunque «sólo» lo hemos dicho, ese bien es el bien que complace.

El cálculo es la admisión de Hutcheson de que no sólo varían las concepciones de la benevolencia, sino que ésta no se impone por entero de una forma ideal, como trayendo al mundo todas las esperanzas de la razón; por el contrario, admite grados: «existe una determinación universal en la humanidad hacia la benevolencia (...) pero no debemos imaginar que esta benevolencia es igual o del mismo grado hacia todas las cosas» (Inquiry, secc. 5, I). Mc interesa señalar a la benevolencia no como un catecismo con cuya obediencia se cumpla el mundo feliz, sino más bien como un compendio de buenas respuestas que han de ser sopesadas, computadas dice Hutcheson, con distintos factores. Por ello, convencido de que la benevolencia se expresa en grados, Hutcheson nunca dice que unas pasiones - benevolentes- hayan de anular a otras - cgoístas-, sino que han de primarse unas ante otras. Es consciente nuestro autor de que es imposible arrinconar el mal en cl mundo; de hecho, el balance moral supone reconocer al mal como componente de muestra realidad y, por ende, como constitutivo de la propia identidad, en tanto nos configuramos en una constante actuación balanceada entre la benevolencia y el egoísmo. No es que el mal sea connatural al hombre, sino más bien que el mal es simplemente la posibilidad de que nuestros propios intereses primen sobre los intereses sociales, de que nuestro juicio y nuestos actos no se inclinen hacia la benevolencia [bien porque no seamos capaces de percibir correctamente las afecciones de una acción (Illustrations, p. 283), bien porque la cercanía nos lleve a ser «más benevolentes» con quienes nos son más próximos (Illustraitons, p. 303)].

Aquí se sitúa el cálculo que balancea pros y contras, benevolencias cercanas y lejanas con intereses privados y públicos. El cálculo repasa su balance y dicta sentencia: esta actuación es de mayor mérito y aquélla de menos. Pues bien, me interesa subrayar que, si tiene sentido el evaluar las acciones en 
función de la cantidad de bien público que hayan proporcionado, es porque la actuación benevolente no es absoluta. La benevolencia no se consigue en cada acto que la persigue; se da por pedazos, nombrándola a retazos, construyéndola en las diversas acciones que diciéndola por partes no la dicen por completo. Es así como se forma una sociedad de hombres y mujeres y, por lo demás, es así como se configuran csos hombres y mujeres.

\section{El Sistema}

Los individuos calculamos porque nuestro propio sentido moral autónomo así lo implica: somos cada uno en particular quienes hemos de ir evaluando lo que nos complace en cada momento. Pero el cálculo tiene también en cuenta que aun siendo un cálculo motivado por la propia autonomia, ha de hacer relación y referirse a la comunidad con referencia a la cual surge el placer o displacer del sentido moral; a esa comunidad se dirigen nuestras acciones benevolentes y de esa comunidad se obtienen las virtudes y términos que definen lo que va a ser el bien público. Hutcheson piensa en el cálculo como una sencilla operación que integra la autonomía en la comunidad. Pues bien, con esa sencilla operación se conforma un Sistema.

El sentido moral no es una norma, porque «iqué norma sobre las acciones puede formarse sin ninguna conexión con algún fin propuesto? No será fácil explicar qué fin pucda proponerse sin presuponer instintos, deseos, inclinaciones o un sentido moral» (Illustrations, 284). Ni regla, ni norma. El sentido moral es, más bien, un proceso, un constante hacer balance entre bencvolencia e interés propio, entre nuestra vida desapegada del mundo -como la de un átomo social-y una benevolencia que presenta el estándar moral en el cual se nos dan las diferentes maneras de ser benevolentes - de preocuparnos por el bien público-. Un estándar moral que sin ser estable, ni fjo, ni eterno, sí que es el último punto donde se acaba la argumentación. Y esto es lo verdaderamente universal del juicio moral: que el bien público es la última referencia de nuestra vida en el mundo. ¿Cómo se juzga la corrección de ese último punto, el que sea bueno o no? Bien, al final la contextualidad de la benevolencia hace que el sentido moral se convierta en un talante, un modo de afrontar el mundo, una manera de ser honrado, de educar para serlo y de vivir en comunidad. ¿Cuáles son las virtualidades de ese sentido moral? Aquí la respuesta de Hutcheson es simplemente que gracias a nuestro sentido moral somos capaces de componer una buena vida (una vida tan hermosa que nos da placer y felicidad) y que asumiendo un determinado tipo de benevolencia, de bien público, definimos un Sistema, una comunidad.

Dice Strasser que Hutcheson piensa que el único camino de la felicidad es satisfacer nuestro sentido moral, nuestro sentido público y nuestro sentido del honor, es decir, complaccrnos con el bien público y ser reconocidos públicamente. Siendo esto así, teniendo hombres y mujeres naturalmente un sentido 
moral y, por añadidura, un sentido público y un sentido de lo que es humano -i.e., un sentido de dignidad y honor-, es fácil reclamar la cercanía de todos los individuos y su natural tendencia a la comunidad en la que generalmente acuerdan (Strasser, 1987, p. 527). Esta idea creo que ha de scr matizada en el sentido de que, no es solamente que de tal modo sea más fácil reclamar la pertenencia a una misma comunidad, es que, adcmás, cse scntido moral de la politica y del hombre se toma de una comunidad con la que el individuo cuenta de manera implícita siquiera para tener sus primeras palabras, los primeros términos y la primeras jerarquías de significado. Comunidad que, además, se promueve y modifica a través del trabajo del sentido moral (esto es, del sentido de lo que es humano y del sentido de lo público). Hutcheson hace más hincapié en el aspecto de cercanía de los hombres por tener todos un sentido moral, pero no es menos cierto que en más de una ocasión nos recuerda que, si tenemos un sentido de benevolencia - que como muy bien ve Strasser es un sentido de lo público y de la propia identidad-, es porque lo tomamos del Sistema, al cual, de hecho, ya pertenecemos. Y aquí no hay primeros términos: no es primero la comunidad y luego la benevolencia, ni ésta antes que aquélla; por el contrario, entre ambas se establece una coincidencia más que una relación, una superposición no siempre coordinada en la cual se dirimen nuestras vidas (por eso sobre este tema Hutcheson nunca es sistemático y nos habla de esto en todas partes y a propósito de cualquier cosa).

El sentido moral se complace en cuanto es capaz de hacerse heredero de toda una historia, de todos unos asentimientos, de todas las metáforas de la virtud en las que cobra consistencia el mundo social: la felicidad que complace al sentido moral incorpora al Sistema al completo. $Y$ a la inversa también es cierto: la benevolencia forma un sistema público donde la compasión, la disposición de derechos y libertades, y la deliberación de motivos morales ( $\tan$ diversos como si son preferibles los labios finos o los carnosos, acerca de la bondad de la confianza mutua en el matrimonio o sobre cuál es la diferencia entre comercio y usura) configuran un Sistema, el del bien público, en el que nuestra única autoridad para entrar, discutir, diferir y promover actuaciones es simplemente que tenemos un sentido moral que nos capacita a todos para hablar. El Sistema como lugar en donde nos encontramos con otros y compartimos con esos otros el mundo es siempre el que, en última instancia, da sentido a toda la construcción de Hutcheson. Su idea (en esto totalmente dieciochesca) es que el sentido de honor y vergüenza tienen mucho que decir a la hora de la actuación y que, si bien es cierto que actuamos y nos complacemos desde nosotros mismos — con nuestro sentido moral propio y autónomo-, no lo es menos que siempre buscamos la aprobación de los demás (y nos avergonzamos con su reprobación). La vida que Hutcheson propone entre el sentido moral, la benevolencia y el cálculo, es el constante trabajo de concertar mi propio mundo con el existente en un Sistema.

No creo hacer mucha traición a nuestro autor si digo que yo no me puedo complacer sin el otro. Y si es cicrto que para que ese otro pueda entrar en 
mi cálculo de placeres ha de formar parte de mi sistema comunitario (y desde ese punto de vista ha de ser parecido a mí, tener mi mismo idioma social, usar mis mismos términos, en suma, es preciso que conmigo forme un nosotros más o menos claro), también es cierto que la misma composición contingente de los sistemas les posibilita cambiar, que los gustos también cambian, que aquello que hoy es útil no lo es mañana y que, en fin, por ampliar el uso de los anacronismos, si la cerrazón comunitaria es fuerte, no lo es menos el último reducto autónomo del sentido moral. De su placer, al cabo, depende el sí o el no.

\section{BIBLIOGRAFIA}

Campbell, T. D., "Francis Hutchcson: "Fathcr" of Scottish Enlightenment", incluido en R. H. Campbell y A. S. Skinner (eds.), The Origins and Nature of the Scottish Enlightenment, Edimburgo, John Donald Publishers, 1982.

DarwaLl, S., British Moralists and the Internal «Ought», Cambridge University Press, 1995.

FAte Norton, D., “Hutcheson's Moral Realism», en Joumal of the History of Phitosophy, núm. 3, vol. 23, julio de 1985, pp. 397-418.

Hakonssen, J., Natural law and moral philosophy, Cambridge University Press, 1996.

Hore, V. M., Virtue by Consensus. The Moral Philosophy of Hutcheson, Hume and Adam Smith, Oxford, Clarendon Press, 1989.

Hutcheson, $\mathrm{F}$, An Inquiry into the Original of our Ideas of Beauty and Virtue in two Treatises, Londres, 1725. Reproducción facsimil en Hildesheim, Georg Olms Verlagsbuchhandlung, 1971 (se cita como Inquiry).

- An Essay on the Nature and Conduct of the Passions and Affections with Illustrations on the Moral Sense, Londres, 1730. Reproducción facsímil en Hildesheim, Georg Olms Verlagsbuchhandlung, 1971 (se cita como Essay el primer libro y como Illistrations el segundo). En este libro sigo la traducción aún inédita que Roberto Rodriguez Aramayo y Mirtha Hernandez han realizado del mismo.

- A System of Moral Philosophy, Glasgow, 1755. Reproducción facsímil en Hildesheim, Georg Olms Verlagsbuchhandlung, 1971 (se cita como System).

Jensen, H., Motivation and the Moral Sense in Hutcheson, La Haya, Martinus Nijhoff, 1979.

Roberts, T. A., The Concept of Benevolence. Aspects of the Eighteenth-Century Moral Philosophy, Londres, MacMillan Press, 1973.

SCHNEEwInd, J. B., The invention of autonomy. A history of modern moral philosophy, Cambridge University Press, 1998.

ScoTr, W. R., Francis Hutcheson. His Life, Teaching and Position in the History of Philosophy, Nueva York, Augustus M. Kelley, 1966 (es una reedición del original de 1900).

SHER, R. B., «Professors of Virtue: the Edinburgh Chair», incluido en M. A. Stewart (ed.), Studies in the Philosophy of the Scottish Enlightenment, Oxford, Clarendon Press, 1990.

Sprague, E., «Francis Hutcheson and the Moral Sense», en The Joumal of Philosophy, núm. 51 , año 1954, pp. 794-800. 
STAFFORD, J. M., «I lucheson, Hume and the Ontology of Morals», en Joumal of Value Inquiry, núm. 2, vol. 19, 1985, pp. 133-151.

Stecker, R. "Thomas Reid on the Moral Sense», en The Monist, vol. 70, octubre 1987, pp. 453-464.

SItwart, M. A. (ed.), Studies in the Philosophy of the Scottish Enlightenment, Oxford, Clarendon Press, 1990.

Stewart, R. M., «John Clarke and Francis Hutcheson on SelfLove and Moral Motivation", en Joumal of the History of Philosophy, num. 2, vol. 20, julio 1982, pp. 261-277.

Strasser, M., "Hutcheson on the Higher and Lower Pleasures», en Joumal of the History of Philosophy, núm. 24, 4 de octubre de 1987, pp. 517-531.

- Francis Hutcheson's Moral Theony, New Hampshire, Longwood Academic, 1990.

WinkLER, K. P., «Hutcheson's Alleged Realism», en Journal of the History of Philosophy, núm. 23, 2 de abril de 1985, pp. 179-194. 